\title{
VÍNCULOS ENTRE LA ESCUELA AUSTRIACA DE ECONOMÍA Y EL MÉTODO DE LA INVERSIÓN EN VALOR
}

\author{
DiEgo E. QUIJANO DURÁN*
}

Resumen: La Escuela Austriaca de Economía y el método de inversión en valor tienen una concepción similar del mundo que permite entrelazarlas coherentemente. Al economista, le permite profundizar el conocimiento del ejercicio de la función empresarial y la realización del cálculo económico en la práctica. Al inversor, le ofrece un marco teórico para comprender mejor el papel del empresario y los fenómenos económicos y detectar temprano patrones peligrosos y así protegerse. En este trabajo partimos de la base de que ambas escuelas de pensamiento tienen sus raíces en el sentido común y los supuestos realistas, que son prudentes a la hora de ver el futuro y que dudan de la utilidad de las matemáticas complejas en los campos económicos y financieros. Sobre ello, desarrollamos nueve aspectos en los cuales hay fuertes conexiones como, por ejemplo, la manera en que el ejercicio de la empresarialidad mejora la eficiencia del mercado y coordina los planes de las personas.

Palabras clave: Inversión en valor, escuela austriaca de economía, empresarialidad, eficiencia dinámica, cálculo económico.

Clasificación JEL: A12, G17, M20.

Abstract: The Austrian school of economics and the investment method known as value investing have a similar conception of the world, so that it is possible to find multiple links between them and form a coherent structure. To the economist, this allows for a much deeper understanding of the entrepreneurial function and the manner in which economic calculation

* Máster en Economía de la Escuela Austriaca por la Universidad Rey Juan Carlos de Madrid y cofundador y directivo del Instituto de Estudios para una Sociedad Abierta (ISA) en Panamá. Email: de.quijano@gmail.com

Procesos de Mercado: Revista Europea de Economía Política Vol. IX, n.. 1, Primavera 2012, pp. 255 a 304 
is actually performed. To the investor, it offers a theoretical framework that explains economic phenomena, permitting him to better understand the role of the entrepreneur and to protect his investment when dangerous patterns can be observed. In this essay, we begin from the common stance of both schools of thought towards common sense, the use of realistic assumptions, the importance of prudence and the low value of complex mathematics in the fields of economics and finance. We then proceed to develop in greater depth nine aspects that have strong philosophical and scientific links.

Key words: Value investing, Austrian school of economics, entrepreneurship, dynamic efficiency, economic calculation.

JEL Classification: A12, G17, M20.

To value investors, Austrian economics is (or should be) compelling because it subsumes real economic and financial events within justifiable laws of human action. Unlike mainstream economic and finance, Austrians not only acknowledge but also emphasise the importance of entrepreneurship [...]. In turn, value investing and the results achieved by prominent value investors may interest Austrians because Grahamites hold [...] views that are compatible to Austrian views-with respect to important economic and financial principles. Value investors also illustrate the positive results that entrepreneurial action can achieve. Despite the many follies of governments and mainstream economists and investors, which often prompt value investors and Austrians alike to adopt rather dour short-term outlooks, both Grahamites and Misesians are longterm optimists. To adopt their approaches to economics and investment is ultimately to affirm a basic faith in human nature, capitalism, one's country and a future that will be at least as prosperous as the present.

Chris Leithner $(2005,20)$ 
If you know that the economy is dominated by the time-bound structures of production and speculation, the world comes into clearer focus. [...] What we do is look for extremes in markets: very undervalued or very overvalued. Austrian theory has certainly given us an edge. When you have a theory to work from, you avoid the problem that comes with stumbling around in the dark over chairs and night stands. At least you can begin to visualize in the dark, which is where we all work. The future is always unlit. But with a body of theory, you can anticipate where the structures might lie.

JAMES GRANT (1996)

\section{I \\ INTRODUCCIÓN}

En el mundo financiero, el método de inversión conocido como la inversión en valor (value investing) ha demostrado, a través de sus principales practicantes, ser capaz de generar ganancias sustanciales a lo largo del tiempo. Aun así, es un método que se encuentra en desuso. De manera similar, en las ciencias económicas, hay un paradigma que ha sido muy fértil a la hora de explicar los fenómenos económicos y que, sin embargo, se mantiene como una corriente marginal. Se trata de la escuela austriaca de economía.

Si bien el porqué de la impopularidad de estas dos escuelas puede ser un tema interesante para investigar, la motivación de este análisis yace en el hecho de que ambas comparten un mismo fundamento epistemológico. Resulta natural querer relacionarlas porque tanto en la inversión en valor como en la economía austriaca prepondera el sentido común - cualquiera es capaz de comprender sus principios-, se recalca la importancia de utilizar supuestos realistas, hay una gran humildad ante la posibilidad de predecir el futuro y se rechaza la utilidad de las matemáticas complejas para el análisis económico y financiero.

Claro está, los objetivos de cada una son distintos. El método de la inversión en valor busca aumentar las posibilidades de 
ganancias y minimizar las de pérdidas, mientras que la escuela de economía austriaca ofrece un marco teórico para analizar y comprender los fenómenos económicos. Dada esta diferencia, ¿se pueden encontrar vínculos entre ambas metodologías que le sean útiles, por un lado, al economista y, por el otro, al inversor? Pensamos que sí. Ambos especialistas pueden encontrar provechosa, para el desempeño de su actividad, una mayor comprensión de la materia del otro. Al inversor le será útil porque comprenderá el origen de las ganancias o pérdidas de las empresas en que pretende invertir, desinvertir o no invertir y la importancia que tiene para la sociedad la ejecución de la actividad empresarial y la suya como inversor, y le ayudará a protegerse al obtener las herramientas para identificar patrones de tendencia peligrosos. Para el economista, conocer el método de la inversión en valor le permite profundizar su comprensión del ejercicio de la función empresarial y un método práctico, que ha sido muy exitoso, de realizar el cálculo económico para determinar el mejor uso del capital.

En la primera parte de este ensayo realizaremos una introducción breve a la escuela austriaca de economía y al método de la inversión en valor. Con esta base, profundizaremos sobre las cuatro características ya mencionadas: el sentido común, los supuestos realistas, la prudencia y el uso de las matemáticas. En la segunda parte, abordaremos nueve aspectos en los cuales existe una relación clara entre la inversión en valor y la escuela austriaca. Estos nueve puntos son: 1) el significado de las acciones ordinarias; 2) la valoración de una empresa; 3) la forma en que se asignan los bienes de capital; 4) el ejercicio de la empresarialidad y la eficiencia dinámica del mercado; 5) la debilidad de los modelos matemáticos; 6) la humildad ante las posibilidades de predicción; 7) el concepto de riesgo; 8) la crítica a los Mercados Eficientes; y 9) el significado de las ganancias empresariales. Por último, realizaremos unos comentarios a modo de conclusión. 


\title{
PRIMERA PARTE
}

\author{
I \\ LA ESCUELA AUSTRIACA DE ECONOMÍA
}

Esta escuela se centra en el estudio de la acción humana, es decir, que las personas son las protagonistas de los fenómenos económicos y, por ello, deben ser parte fundamental del estudio de la economía. No obstante, la ciencia económica no se ocupa de las motivaciones específicas de las acciones que toma cada persona, ni de la valoración ética de esas acciones, ni de los principios, ideales o metas que las guían. La ciencia económica, tal como la visualiza la escuela austriaca, parte de reconocer el hecho incontrovertible de que cuando las personas actúan lo hacen en pos de los fines que más valoran en ese momento y utilizan los medios a su disposición que consideran más útiles para alcanzarlos. Todo ello se basa en una concepción del hombre como un ser con libre albedrío, y no un autómata. Este ser libre es capaz de transformar el mundo físico que lo rodea e interrelacionarse con otras personas mediante la comunicación, el intercambio y las promesas para alcanzar sus distintos objetivos.

El economista Ludwig von Mises (1881-1973), uno de los principales exponentes de la escuela austriaca, señala en este sentido:

El individuo advierte mentalmente la utilidad de los bienes, es decir, su idoneidad para conseguir resultados apetecidos; y al actuar, los convierte en medios. Es de capital importancia observar que las cosas integrantes del mundo externo sólo gracias a la operación de la mente humana y a la acción por ella engendrada llegan a ser medios. Los objetos externos, en sí, son puros fenómenos físicos del universo y como tales los examinan las ciencias naturales. Pero mediante el discernimiento y la actuación humana se transforman en medios. La praxeología [el estudio de la acción humana], por eso, no se ocupa propiamente del mundo exterior, sino de la conducta del hombre al enfrentarse con él; el universo físico per se no interesa a nuestra ciencia; lo que ésta pretende es analizar la consciente reacción del hombre ante las realidades objetivas. La teoría económica no trata sobre cosas y objetos materiales; trata sobre los hombres, sus apreciaciones y, consecuentemente, 
las acciones humanas que de aquellas se derivan. Los bienes, mercancías, la riqueza y todas las demás nociones de la conducta, no son elementos de la naturaleza, sino elementos de la mente y de la conducta humana. Quien desee entrar en este segundo universo debe olvidarse del mundo exterior, centrando su atención en lo que significan las acciones que persiguen los hombres. ${ }^{1}$

Es importante recalcar que la economía no se interesa por la condición material per se, excepto cuando ello implica un punto de partida sobre el cual se realizarán las acciones humanas, las cuales son capaces de alterar ese mismo contexto, de tal forma que sea posible alcanzar objetivos que antes eran inviables. Inherente a esta visión de la economía está la idea de que las personas aprenden de sus errores y éxitos (y de los errores y éxitos de otras personas). Eso implica que pueden modificar los fines que más valoran, así como la percepción de la utilidad de los medios disponibles. Por ello, el énfasis en la escuela austriaca no está en el estado de equilibrio final, sino en el estudio del mercado como un proceso de interrelaciones entre personas, cada una de las cuales está persiguiendo sus fines y va adaptando y modificando su comportamiento (y los propios fines) de acuerdo con las circunstancias que encuentra en el mundo externo y la capacidad de alcanzarlos.

Si las personas somos las protagonistas de los fenómenos económicos, entonces la economía estudia procesos dinámicos e impredecibles y, por tanto, difícilmente modelables en relaciones matemáticas. Como explica el profesor Alberto Benegas Lynch (h),

las ciencias sociales se diferencian de las naturales en que en estas últimas hay re-acción mientras que en las primeras hay acción, esto es, propósito deliberado. En las [naturales] existe regularidad y, por ende, hay constantes: a determinado estímulo se produce cierta reacción si se repiten las mismas condiciones. En la acción humana, en cambio, hay decisión, hay libre albedrío y, por ende, ante determinado estímulo la acción procede conforme a las valorizaciones y apreciaciones subjetivas y particulares del sujeto actuante. $^{2}$

\footnotetext{
1 Mises (2009), pp. 111-112.

2 Benegas Lynch (2011), p. 62.
} 
Sin embargo, a pesar de esta falta de regularidad, como parte del proceso de mercado surgen órdenes espontáneos que permiten la mejor coordinación de la infinidad de planes y acciones de los distintos individuos que conforman la sociedad. ${ }^{3}$ Algunos de esos órdenes espontáneos, que han nacido y evolucionado con el pasar del tiempo, terminan constituyéndose como instituciones sin las cuales ni la civilización moderna ni la vida de millones de personas se pudiera dar. Ejemplos de ello son el derecho, el dinero y la familia. Son instituciones que nacieron en un pasado lejano como medidas para reducir la incertidumbre inerradicable. Estas permitían que cada cual fuese planificando sus acciones a plazos cada vez más lejanos gracias a la previsibilidad que estas instituciones dan al comportamiento de otras personas, como por ejemplo, el contrato de trabajo.

Por consiguiente, según nos explica el economista Gabriel Zanotti, la escuela austriaca se distingue por no ser una ciencia instrumentalista, «donde no es relevante la verdad de las premisas del modelo, sino el éxito de las predicciones inferidas a partir de él». Por el contrario, se caracteriza por su visión realista, es decir, que el mercado «es un proceso dinámico, que [...] supone errores e incertidumbres por parte de sus sujetos actuantes» en el que «hay determinadas "fuerzas equilibrantes" [como la empresarialidad] que hacen tender al mercado a una situación de equilibrio, aunque sin alcanzarla nunca». ${ }^{4}$

\section{II}

\section{EL MÉTODO DE LA INVERSIÓN EN VALOR}

El método de la inversión en valor o el value investing se puede identificar, primeramente, como una metodología que enfatiza el análisis de los fundamentos financieros de las empresas. El enfoque no está en el comportamiento histórico del precio de la acción en el mercado de valores, sino en intentar determinar cuál

\footnotetext{
${ }^{3}$ Para un tratamiento detallado sobre los órdenes espontáneos y las instituciones evolutivas, véase Martínez Meseguer (2006).

${ }^{4}$ Zanotti (2004), p. 24.
} 
es el valor razonable de la empresa basándose en su historial financiero, una evaluación de sus características, su sector, su administración y sus ventajas competitivas. La técnica es similar a la que se utilizaría a la hora de determinar el valor de una empresa cuyas acciones no cotizan en una bolsa de valores. Una vez estimado el valor o, más bien, el rango de posibles valores de una empresa, ya que se trata siempre de una estimación subjetiva, el método exige que éste se compare con el precio de la acción en el mercado. La idea es sencilla: el inversor debe comprar si el precio al que puede comprar está muy por debajo del valor estimado por él y no comprar (o vender, si ya se tiene en cartera) si está muy cerca, o por encima, de este valor estimado.

El horizonte de inversión para el que practica este método es el largo plazo, de 10 años. Dado que el inversor en valor generalmente busca buenas empresas que se encuentran, según su juicio, subvaloradas y que, por tanto, reciben poca atención de la gran mayoría de analistas financieros, generalmente toma mucho tiempo para que los otros actores del mercado reconozcan el valor subyacente de esta empresa. Por ello, suele decirse que si bien el método de la inversión en valor ofrece las herramientas intelectuales para realizar un buen análisis financiero, en última instancia, lo que más requiere el inversor en valor es mucha paciencia, para esperar durante varios años, manteniendo opiniones que van opuestas a las tendencias más populares del momento. Además, debe tener el carácter para aguantar caídas temporales en el valor de mercado de su inversión. Si el inversor ha hecho su análisis correctamente y ha comprado a un precio barato, podrá dormir con tranquilidad dada la seguridad que tiene en la estimación que ha hecho. Por tanto, el inversor en valor debe ser sumamente realista y conservador en sus proyecciones, porque el problema está en equivocarse hacia las bajas. Si se es prudente, se evitará comprar a la expectativa de que ocurra el escenario más optimista. Por último, el inversor en valor no utiliza el análisis técnico y es consciente de su papel como asignador de capital.

Benjamin Graham (1894-1976) es considerado su principal exponente y el padre de la metodología dada su labor educativa y diseminadora al publicar las obras Security Análisis (1934 con David Dodd) y The Intelligent Investor (cuya última edición 
es de 1973). Hoy día, el empresario americano Warren Buffett es tal vez el practicante más reconocido de este método junto con otros inversores como Philip A. Fisher (1907-2004), Peter Lynch, Seth Klarman, John Templeton, Joel Greenblatt y Jim Rogers.

Graham afirmó que si tuviese la necesidad de resumir en una sola frase la regla de inversión más importante sería: un margen de seguridad. Contar con un margen de seguridad permite minimizar las posibilidades de pérdidas irreversibles, aumentar las posibilidades de ganancias sustanciosas y sostenidas en el tiempo y limitar las ocasiones en que se sobrepaga por una empresa. El mensaje fundamental es que la inversión en una empresa no se puede desligar del precio de compra. Si a ello se le suma un proceso riguroso de selección de empresas bien gestionadas, con ventajas competitivas y un modelo de negocio sostenible que el inversor comprende, se establecerán las mejores posibilidades para una inversión exitosa.

Cabe notar que para el economista de la escuela austriaca el término «inversión en valor» es cacofónico. Si las valoraciones son siempre subjetivas, ¿cómo puede haber otra cosa que no sea una inversión en valor? Buffett coincide y señala que «Nosotros pensamos que el mismo término "inversión en valor" es redundante. ¿Qué es el "invertir" si no es otra cosa que el acto de buscar valor que sea al menos lo suficientemente alto para justificar el importe pagado?». ${ }^{5}$ Se trata de un asunto semántico. El término «inversión en valor» o «valor intrínseco» resume el método de búsqueda de empresas que están subvaloradas en el mercado, según la estimación del inversor. La inversión en valor es comprar a un precio barato algo que es capaz de generar mucho más de lo que su precio actual indicaría y que, al ser capaz de generar mucho más, en realidad tiene un valor mayor que el que tiene en el mercado. ${ }^{6}$ En este ensayo utilizaremos los términos la inversión en valor o value investing para identificar un método y nunca para referirnos a la existencia de un valor intrínseco independiente del proceso de mercado.

\footnotetext{
${ }^{5}$ Buffett (2008), p. 100. Traducción libre.

6 Para una breve explicación de cómo funciona este método en la práctica véase Quijano Durán (2011).
} 


\section{III \\ UN PUNTO DE PARTIDA}

Estas dos introducciones han sido realizadas para proporcionar una base con la que enmarcar la discusión sobre los distintos principios económicos y financieros que comparten la inversión en valor y la escuela austriaca. Cabe ahora elaborar algunas de las ideas mencionadas en la introducción. Se trata de conceptos con los que de manera implícita o explícita nos volveremos a topar una y otra vez a lo largo de este análisis: el sentido común, los supuestos realistas, la prudencia y el uso que ha de darse a las matemáticas.

Dice el aforismo popular, a veces atribuido al poeta español Antonio Machado, que el sentido común es el menos común de los sentidos. De ser así, ¿qué queremos decir al insistir que tanto la inversión en valor como la escuela austriaca utilizan el sentido común? En suma, que el conocimiento necesario para empezar a comprender y utilizar ambos marcos teóricos es muy elemental, sin requisitos de formación en sofisticadas técnicas matemáticas o conocimientos muy abstractos.

Así, puede afirmarse que el sentido común nos diría, tal como lo enfatiza el método de la inversión en valor, que si se está considerando realizar una inversión en una empresa, lo más razonable sería no ignorar su situación financiera, ni su negocio, ni el precio al que se puede comprar. Y que si queremos hacer una proyección sobre la posible evolución de la empresa en el futuro, no debemos considerar el escenario más optimista como punto de referencia para tomar una decisión de inversión, sino más bien un escenario muy conservador como una forma de protección.

De la misma forma, en las ciencias económicas, el sentido común nos indicaría que es preferible utilizar supuestos reales como una base sobre la cual desarrollar una teoría económica. ${ }^{7}$ A diferencia del análisis financiero de una empresa, en el que se está analizando el comportamiento de una organización específica y su

\footnotetext{
7 Sobre el uso de supuestos reales, véase Long (2006).
} 
posible desempeño en el futuro, para la escuela austriaca, cuando nos referimos a supuestos realistas no estamos hablando de estadísticas económicas conservadoras, sino de supuestos teóricos apegados a la realidad. Como veremos más adelante, los economistas austriacos enfatizan la dificultad (o imposibilidad) de realizar predicciones científicas en economía debido a la enorme cantidad de variables, que afectan a cada fenómeno. A ello se debe agregar la dificultad de que el grado de influencia de cada variable fluctúa con el paso del tiempo. A la hora de hacer predicciones económicas, se debe ser prudente y aceptar que no podemos más que hacer referencia a los patrones de tendencia que suelen ocurrir cuando existe una conjunción particular de una serie de circunstancias.

En cuanto al uso de las matemáticas, el método de la inversión en valor se despoja de todas las pretensiones de las matemáticas financieras más avanzadas, regresando al uso de las relaciones contables básicas y enfatizando la importancia de su interpretación. Más allá de la aritmética y el álgebra básica, no se utilizan herramientas más sofisticadas. Ello no quiere decir que se trata de un rechazo absoluto a las matemáticas, sino de enfatizar el hecho de que no son las matemáticas y su aparente precisión lo que dispensa el conocimiento necesario para tomar decisiones más o menos acertadas a la hora de invertir. Graham insiste, por ejemplo, en señalar que la mayoría de los inversores que utilizan el llamado enfoque técnico (technical approach) para evaluar títulos que cotizan en una bolsa, se guían por principios que son diametralmente opuestos a los utilizados para determinar la sensatez de un negocio en cualquier otro ámbito. ${ }^{8}$

En economía, el uso de las matemáticas se enfrenta a dos obstáculos insalvables. El primero es, como dice el economista Juan Carlos Cachanosky, que «No todo lo que se dice en palabras es traducible a matemática, pero toda formulación matemática es traducible a palabras». ${ }^{9}$ Cachanosky apunta que el uso de símbolos comenzó, primero, como una forma de economizar el lenguaje: es más corto escribir « $2+2=4 »$ que «dos más dos es igual

\footnotetext{
8 Graham (2006), p. 2.

9 Cachanosky (1986), p. 5.
} 
a cuatro", pero su significado sigue siendo igual de riguroso y exacto; $y$, segundo, para facilitar las operaciones a la hora de calcular. Sin embargo, a pesar de la aparente precisión que podrán tener las formulaciones matemáticas más complejas, cuando se compara con la realidad, la formulación verbal muchas veces será más cierta y exacta. Por ejemplo, el uso de derivadas para calcular la demanda de un bien, implicaría que existe una continuidad en la relación entre precio y cantidad, cuando en realidad lo que hay es unidades no fraccionables (carros, casas, pantalones, emparedados, etc.). Una descripción verbal de este fenómeno es más fiel a la realidad y, de hecho, más precisa al no implicar que existe esa continuidad.

El otro obstáculo que confrontan las matemáticas es que se pretende utilizarlas como una forma de conocer más sobre la realidad. Carl Menger (1840-1921), economista considerado como el padre de la escuela austriaca, en una carta de 1884 que escribió a Léon Walras, se preguntaba: «¿Cómo se podrá alcanzar el conocimiento de la esencia, por ejemplo, del valor, de la renta de la tierra, del beneficio empresarial, de la división del trabajo, del bimetalismo, etc., mediante métodos matemáticos?». ${ }^{10}$ La matemática puede utilizarse como una herramienta para facilitar el análisis o ilustrar una idea, pero la comprensión de los fenómenos económicos no vendrá del análisis que se haga de un modelo matemático. Para comprender los conceptos de precio o beneficio empresarial se requiere de la valoración de los sujetos actuantes que los están interpretando y ocasionando.

Mises también critica severamente al método matemático en la economía: «El método matemático ha de ser recusado no sólo por su esterilidad. Se trata de un sistema vicioso que parte de falsos supuestos y conduce a erróneas conclusiones» y luego coincide con Menger señalando que «Sus silogismos no sólo son vanos, sino que distraen la atención de los verdaderos problemas, deformando la concatenación existente entre los diversos fenómenos económicos». ${ }^{11} \mathrm{Y}$, sin embargo, luego, como una muestra de que no se trata de un rechazo a las matemáticas per se, para facilitar

\footnotetext{
10 Huerta de Soto (2007), p. 34.

11 Mises (2009), p. 422.
} 
la comprensión del concepto de la división del trabajo, Mises recurre a la aritmética. ${ }^{12}$

De igual forma, en la inversión en valor, se usan las matemáticas para analizar los balances y estados de resultados de las empresas. Pero estas operaciones, como los diversos métodos de cálculo de rentabilidad, son operaciones matemáticamente sencillas que son útiles sólo porque se cuenta con la información necesaria y el marco teórico que explica la importancia, utilidad, fortaleza o debilidad de cada uno de los indicadores, todo lo cual es necesario poner en perspectiva con la situación del negocio, su gestión, su historia, su proyección de futuro y el precio de compra. Se trata de interpretaciones subjetivas. No cabe pensar que exista un último y único indicador objetivo que sirva de determinante para una decisión de inversión.

La razón por la que se pone tanto énfasis en el sentido común, los supuestos reales, la prudencia y que se evite el uso de las matemáticas complejas, es que en el ámbito de la acción humana y, por tanto, en el empresarial, el futuro es incierto. En este ámbito, como se ha dicho, hay decisiones y libre albedrío; el futuro es un porhacer y no un simple porvenir, como suele recalcar el economista Jesús Huerta de Soto. Por lo tanto, basar las decisiones de inversión sobre cálculos de lo que hará un título bursátil en el futuro o calificar la ciencia económica por su capacidad predictiva, no tiene sentido. El análisis económico y financiero no puede desvincularse de la realidad subyacente, es decir, carece de lógica (1) comprar una acción como si ésta no tuviera relación con la operación empresarial que subyace y (2) realizar un análisis económico con base en modelos con supuestos irreales.

Dicho esto, en la siguiente parte profundizaremos sobre nueve aspectos que muestran la compatibilidad y complementariedad entre la escuela austriaca de economía y el método de la inversión en valor.

\footnotetext{
12 Ibíd. pp. 189-190.
} 


\section{SEGUNDA PARTE}

\section{I \\ EL SIGNIFICADO DE LAS ACCIONES ORDINARIAS}

En finanzas, se suele considerar a las acciones ordinarias o comunes como un instrumento financiero de renta variable que surge de la inestabilidad de su retorno. Frente a ellas están los instrumentos de renta fija, como los bonos, que tienen una tasa de interés preestablecida. En efecto, no se puede saber a priori qué rendimiento dará una inversión en acciones, pero sí se puede saber-suponiendo que el emisor no quiebre—cuánto rendirá un bono. Si bien esta distinción es correcta, este modo de analizar los distintos tipos de valores no es suficiente y, más bien, es contraproducente, porque puede llevar a pensar que se puede ignorar la operación empresarial subyacente y que hay una diferencia significativa entre el inversor dueño de acciones de una empresa que no cotiza en bolsa y aquel dueño de acciones de una compañía que sí cotiza.

El hecho es que los instrumentos de renta variable son certificados que otorgan una propiedad proporcional o alícuota, a una serie de activos productivos o bienes de capital de una empresa. El economista Huerta de Soto analiza tanto los instrumentos de renta variable y los de renta fija bajo esta óptica y observa que ambos consisten en la transferencia de recursos ahorrados a cambio de un futuro ingreso mayor. Según nos dice:

Los títulos valores son [...] la encarnación jurídica de las participaciones en las operaciones de concesión de bienes presentes, por parte de los ahorradores y capitalistas, a los demandantes de bienes presentes que están dispuestos a utilizarlos en los procesos productivos a cambio de entregar en el futuro a los ahorradores o prestamistas una cantidad superior de bienes futuros. Estos títulos valores pueden tener a su vez una materialización y naturaleza jurídica muy diversa, pudiendo tratarse de acciones, obligaciones, etc. ${ }^{13}$

\footnotetext{
${ }^{13}$ Huerta de Soto (2009), p. 360.
} 
En otras palabras, como los bienes de capital son producto del ahorro previo destinado a aumentar la capacidad de producción en el futuro, los títulos-valores como las acciones, al ser una representación jurídica de estos bienes de capital, son también la representación del capital que ha sido previamente ahorrado y puesto a producir en una actividad más alejada del consumo final.

La noción sobre la que hacemos hincapié es que en el mercado de valores no se están intercambiando papelitos sin ningún vínculo con la realidad, sino distintos tipos de títulos sobre bienes de capital que están siendo utilizados en una organización. Este concepto de acciones o títulos valores no es innovador, pero es la forma más sensata de entenderlos. «Destacados inversores en valor como los estudiantes y empleados del Sr. Graham como Warren Buffett, Thomas Knapp y Walter Schloss [...] se consideran a sí mismos no como comerciantes de pedazos de papel, sino como emprendedores y dueños de negocios tangibles», dice Leithner. ${ }^{14}$ A su vez, Buffett recalca, en referencia a los inversores de su empresa Berkshire Hathaway, que «Nosotros no vemos a la compañía en sí [Berkshire Hathaway] como la dueña última de nuestros activos empresariales; en su lugar, vemos a la empresa como un conducto a través del cual nuestros accionistas son dueños de los activos». ${ }^{15}$ Graham señala que el inversor "defensivo" "puede ignorar las consideraciones del mercado de valores, si así lo desea, y considerarse así mismo, primordialmente, como un dueño parcial de un negocio bien establecido y rentable». ${ }^{16}$ De la misma manera, uno de los gestores de la firma española Bestinver, que sigue el método de la inversión en valor, Âlvaro Guzmán de Lázaro, coincide al señalar que «Al invertir estamos adquiriendo una parte alícuota de un negocio». ${ }^{17}$

Desvincular el título de propiedad de su negocio puede parecer descabellado, pero cuando se observa que hay economistas que sostienen que las ganancias o pérdidas que se pueden obtener

\footnotetext{
14 Leithner (2005), p. 7. Traducción libre.

15 Buffett (2008), pp. 29-30. Traducción libre.

16 Graham (2006), p. 359. Traducción libre.

17 Guzmán de Lázaro (2008).
} 
en el mercado de valores no pueden distinguirse del azar, como veremos en el apartado octavo, nos percatamos de la importancia de recalcar este concepto. Para tener un éxito sostenido y prolongado en el tiempo, nunca se debe comprar y vender en el mercado de valores sin comprender que lo que se compra es un derecho proporcional sobre una operación empresarial y sus bienes de capital.

\section{II}

\section{LA VALORACIÓN DE EMPRESAS}

El hecho de que las acciones sean la encarnación jurídica de los activos productivos de una empresa, significa que el valor de las acciones de una empresa no se puede independizar de su negocio. Lo que interesa al inversor en valor no es la capitalización de mercado que tiene la empresa hoy, ni el movimiento histórico del precio de la acción, sino el valor que se desprende de la capacidad que se estima que tiene una empresa para generar ganancias futuras.

Esta estimación del valor de una empresa es siempre subjetiva, variará de acuerdo con cada inversor y analista. Debido a la incertidumbre y las condiciones continuamente cambiantes, es científicamente imposible que sea perfecta o exacta. Aun así, se puede hacer referencia a un valor, o rango de valores, que se puede calificar de razonable en el contexto de las circunstancias presentes. Si el ejercicio de valoración se ancla en la realidad de la empresa (sus activos productivos, su equipo de gestión, su negocio y sus ventajas competitivas) y si se utiliza un escenario futuro conservador, se puede proyectar con bastante seguridad el flujo de caja y las ganancias que podrá generar la empresa durante cierto plazo. Esto permite determinar un valor estimado de la operación o la empresa que se encuentra dentro de límites razonables.

El inversor y economista John Burr Williams, cuyo director de tesis doctoral fue Joseph Schumpeter, en su The Theory of Investment Value argumentó que «el valor de cualquier acción, bono o negocio en el día de hoy está determinado por los ingresos y gastos 
de efectivo-descontados por una tasa de interés apropiadaque se puede esperar ocurrirán durante la vida restante del activo». ${ }^{18}$ La clave se encuentra en la última parte de esta explicación y es que el concepto de estimación del valor de un activo o una empresa es sencillo y claro, pero determinar lo que pudiera ocurrir en el futuro es complejo y difícil.

El método de descuento de flujos de caja futuros requiere una enorme cantidad de información como la vida promedio de cada uno de los activos productivos, la vida actual de cada uno de ellos, su coste de operación, su coste de mantenimiento, su coste de reemplazo, los precios a los que se podrá vender su producción, además de una serie de conocimientos prácticos, de circunstancia y lugar que son muy difíciles de adquirir e interpretar correctamente. Aunado a ello, hay que considerar que esos cálculos son sensibles a la tasa de interés que se utilice para descontar la diferencia entre el valor presente y futuro del dinero.

Este concepto de descuento de flujos de caja futuros es equiparable al proceso de valoración marginal de un bien de capital que ocurre en el proceso de mercado según lo desarrolla la teoría austriaca de la estructura inter-temporal del capital. Huerta de Soto apunta al respecto que en el mercado

se incurre en costes porque los agentes económicos piensan que podrán obtener un valor por los bienes de consumo que produzcan superior a aquellos. Lo mismo sucede en relación con la productividad marginal de cada bien de capital, que viene determinada en última instancia por el valor futuro de los bienes y servicios de consumo que el mismo ayude a producir y que, a través de un proceso de descuento, da lugar al valor actual de mercado del bien de capital en cuestión. ${ }^{19}$

El importe que se debe pagar por una acción o un activo está vinculado al retorno que se espera se podrá recibir o generar. Estos flujos de caja futuros y ganancias dependen del éxito de la operación del negocio en el mercado, la capacidad de los mismos en

\footnotetext{
18 Citado por Buffet (2008), p. 101. Traducción libre. Énfasis mío.

19 Huerta de Soto (2009), p. 402.
} 
ser aprovechados por el equipo gestor para que satisfagan de la mejor manera y de la forma más barata las necesidades de sus clientes, sean estos consumidores o empresas intermediarias en el proceso productivo que, a su vez, dependen de poder satisfacer con éxito las necesidades de las empresas que sí satisfacen directamente al consumidor final. El economista Juan Ramón Rallo explica con gran lucidez la idea que intentamos desarrollar y que entrelaza este apartado con el primero:

Las acciones de una empresa no son más que derechos de propiedad sobre factores productivos; su valoración, por tanto, no puede desligarse de la utilidad de los factores productivos, la cual, a su vez, depende en última instancia de la utilidad de los bienes de consumo que contribuyen a producir - los produzcan las propias empresas o sus clientes o los clientes de sus clientes. Así, dado que en una economía dineraria y basada en la división del trabajo, la utilidad de los bienes de consumo puede ser aproximada por el importe monetario por el que se venden [...], podemos concluir que el valor de un factor productivo -o de una estructura de factores productivos empleados de manera complementaria y sinérgica- depende de la suma de sus flujos de caja futuros..$^{20}$

No obstante, dada la incertidumbre que impregna toda realidad empresarial así como la complejidad de muchas empresas, dadas sus distintas líneas de negocio y magnitud de sus operaciones, realizar un descuento de flujos de caja futuros requiere demasiado esfuerzo. Por esta razón, suelen adoptarse métodos que se aproximan al método de descuento de flujos de caja, pero son mucho más sencillos. Francisco García Paramés, gestor de fondos de Bestinver, explica que «No solemos utilizar el método de descuento de flujos de caja, porque el esfuerzo no merece la pena, excepto en el caso de negocios muy estables, como peajes o servicios públicos. En el resto de las empresas, aplicamos múltiplos de flujo de caja libre». ${ }^{21}$ Valorar una empresa con base en un múltiplo del flujo de caja libre, promediado por los últimos cinco

20 Rallo (2011).

21 García Paramés et al. (2007). 
años, simplifica el proceso de estimación sin alejarse del concepto fundamental de descuento de flujos de caja. Si se toman en cuenta las circunstancias de la empresa y se usa un escenario conservador para proyectar hacia el futuro, se puede calcular un múltiplo de flujo de caja libre con lo que se puede determinar una estimación prudente del valor razonable de la empresa, economizando el esfuerzo y tiempo del inversor.

III

\section{LA ASIGNACIÓN DE RECURSOS EN EL PROCESO DE MERCADO}

Tanto los economistas austriacos como los inversores en valor comparten la idea de que en el proceso de mercado se asigna y reasigna el siempre escaso capital a distintas líneas productivas o de actividad económica. La asignación del capital se hará con base en la estimación de futuras rentabilidades, generalmente basándose en el historial de desempeño de la empresa o los activos, pero siempre realizando el análisis de manera prospectiva.

Buffett, por ejemplo, es muy consciente de este papel que desempeña como «asignador» de capital. En una carta a sus accionistas señaló que:

La asignación de capital es crítica para una empresa y la gestión de las inversiones. Porque lo es, creemos que los administradores y los dueños deben pensar mucho sobre las circunstancias en las cuales debe ser retenido y en las cuales debe ser distribuido [...] Las ganancias [...] deben ser retenidas solo cuando hay un proyecto razonable - respaldado preferiblemente por evidencia histórica o, cuando sea relevante, por un análisis cuidadoso del futuro- para que por cada dólar retenido por la corporación, al menos un dólar de valor de mercado sea creado para los dueños. Esto sucederá solo si el capital retenido produce incrementos en las ganancias igual a, o por encima de, las normalmente accesibles para los inversionistas. ${ }^{22}$

22 Buffett (2008), pp. 164-165. Traducción libre. 
En otras palabras, la decisión de reinvertir las ganancias en la empresa o distribuirlas a los accionistas, depende de si, razonablemente, se puede esperar que el beneficio que genere el capital reinvertido será mayor que, o al menos igual a las ganancias que se podrían recibir en otra inversión disponible. Este es, en última instancia, el criterio de asignación de capital desde el punto de vista del cálculo económico. Y es que el capital recibirá su mejor uso en aquellas actividades donde se encuentra el retorno más alto sobre el capital que se invierta, cuestión que volveremos a tratar en el noveno apartado.

Por supuesto, Buffett también comete errores. Reflexionando sobre su política de adquisiciones y ventas de empresas, indicó que:

Somos muy reticentes a vender negocios con un resultado inferior a la norma, siempre y cuando esperamos que sean capaces de generar efectivo y nos sintamos bien sobre sus gestores y las relaciones laborales. Esperamos no volver a cometer los errores de asignación de capital que nos llevaron a esos negocios de calidad inferior. Y también reaccionamos con justa cautela a las sugerencias de que la rentabilidad de nuestros negocios mediocres puede ser recuperada con grandes inversiones en capital fijo. (Las proyecciones serán deslumbrantes y los promotores sinceros, pero, al final de cuentas, las grandes inversiones adicionales en una mala industria son tan gratificantes como una lucha en arena movediza)..$^{23}$

Veamos la similitud de las políticas de inversión de Buffett con el proceso de mercado de la estructura de capital según la describe Huerta de Soto:

La acción [humana...] siempre es prospectiva, nunca retrospectiva. Y los bienes de capital se consideran como tales por el actor siempre en función de la proyectada acción futura, no en función de su entidad material ni de antiguos proyectos de acción. Ahora bien, el pasado, sin duda alguna, influye sobre la acción futura, en la medida en que determina las circunstancias de partida del

23 Ibíd., p. 35. Traducción libre. 
presente. Los seres humanos cometen innumerables errores empresariales a la hora de concebir, emprender y culminar sus acciones $\mathrm{y}$, como consecuencia de ellos, parten para sus acciones ulteriores de unas circunstancias presentes que, de haber sido conocidas con antelación, habrían procurado que fueran distintas. Sin embargo, una vez que los acontecimientos han evolucionado de una determinada manera, el ser humano siempre pretende sacar el mejor partido posible de sus circunstancias presentes [de] cara a la consecución de los objetivos que pretende lograr en el futuro. Además, es preciso tener en cuenta que, si bien los bienes de capital son difícilmente reconvertibles, sin embargo, desde el punto de vista institucional, los inversores logran dotarlos de una importante «movilidad» gracias a las instituciones jurídicas del derecho de propiedad y del derecho de contratos que regulan las distintas formas de transferir dichos bienes. De manera que la estructura productiva (complejísima y muy prolongada) permite una constante movilidad de inversores, que se hace posible gracias al intercambio y a la compraventa de bienes de capital en el mercado.

[El] concepto de capital [...] es distinto, desde el punto de vista económico, del concepto de «bienes de capital». En efecto, definiremos el concepto de capital como el valor a precios de mercado de los bienes de capital, valor que es estimado por los actores individuales que compran y venden bienes de capital en un mercado libre. Vemos, por tanto, que el capital es simplemente un concepto abstracto o instrumento de cálculo económico; es decir, una estimación o juicio subjetivo sobre el valor de mercado que los empresarios creen que tendrán los bienes de capital, y en función del cual constantemente los compran y venden, intentando lograr en cada transacción beneficios empresariales. ${ }^{24}$

Los bienes de capital y las empresas son valorados de manera subjetiva y prospectiva por los inversores, con base en los rendimientos futuros esperados y descontados, partiendo de una situación específica con ciertos supuestos sobre el devenir. Son este tipo de estimaciones las que realiza un inversor en valor, quien luego hará una comparación del valor estimado con el precio que actualmente se pide en el mercado por esos activos.

${ }^{24}$ Huerta de Soto (2009), pp. 225-226. 
Si su estimación es muy superior al precio actual de mercado, significa que podría adquirir esos activos de manera barata y con un buen margen de seguridad, tal como explicamos en el segundo apartado de la primera parte. En este sentido, está realizando el cálculo económico y asignando el capital hacia las áreas donde recibirá un mejor uso.

IV

\section{HACER EL MERCADO MÁS EFICIENTE VALORANDO LAS COSAS CORRECTAMENTE}

Los inversores en valor son conscientes de su papel como «identificadores» de valoraciones erradas en el mercado. Al identificar estos errores de valoración y proceder a invertir en empresas subvaloradas en el mercado de valores, evitar empresas sobrevaloradas y desinvertir en aquellas que ya se aproximan al valor razonable estimado por el inversor, están contribuyendo a ajustar desequilibrios y a coordinar los distintos planes de los participantes en el proceso de mercado.

Recordemos que el método de la inversión en valor exige un horizonte de largo plazo, periodo durante el cual el inversor debe tener mucha paciencia para aguantar los vaivenes del mercado, plazo en el que el valor «liquidativo» de sus inversiones puede ser inferior al valor de compra. Al aplicar el método, evitando las empresas sobrevaloradas e invirtiendo en las subvaloradas, las ganancias que recibirá por la revalorización de su capital serán la recompensa que reciba por haber sido capaz de encontrar empresas subvaloradas que satisfacían las necesidades de sus clientes o consumidores, pero cuya rentabilidad no era reconocida por el mercado. La apuesta es a que la empresa en que se invirtió empezará a mostrar, o continuará mostrando, resultados positivos hasta que el mercado termine por reconocer esa realidad. Como nos recuerda Mises, en última instancia y a largo plazo, «es la reacción de la gente ante el modo en que los inversores ordenaron la producción lo que determina los precios que el mercado de valores registra. En definitiva, es la actitud de los consumidores lo que hace que determinados valores suban, mientras otros 
bajan». ${ }^{25}$ La labor del inversor en valor contribuye a sacar de áreas menos provechosas el capital disponible y colocarlo en áreas en las que está siendo mejor aprovechado para satisfacer de una manera más eficiente y efectiva esas necesidades de los clientes.

Estos movimientos de capital sirven para marcar una pequeña pauta, suponiendo que se ha hecho una estimación acertada sobre el valor razonable y la rentabilidad de las empresas bajo evaluación, para que el resto de los participantes en el mercado también se percaten de esta realidad y se termine de eliminar el desajuste en la valoración de esa organización y su estructura de activos. Este proceso de ajuste se da incluso cuando el inversor decide invertir en una empresa que ha entrado en quiebra y cuya acción se ha desplomado a mínimos en la bolsa de valores. En este caso, el inversor considera que el valor «liquidativo» de los activos de esa empresa son superiores al valor que le está asignando actualmente el mercado.

En este sentido, el gestor de fondos García Paramés reconoce que:

nuestro trabajo consiste en encontrar discrepancias entre los precios actuales, o para ser más exactos, los precios que acaban de formarse en el pasado reciente, y las valoraciones que los agentes van a realizar de los activos en el futuro y que van a determinar los precios futuros. Lo que analizamos, en suma, son discrepancias entre valoraciones subjetivas actuales y valoraciones subjetivas futuras. ${ }^{26}$

Viendo la descripción que hace García Paramés de la labor que realiza, podemos calificar a García Paramés como un empresario kirzneriano. Veamos lo que dice el economista Israel M. Kirzner sobre el papel coordinador que ejerce la función empresarial en el mercado:

Mi concepción del empresario insiste en los aspectos equilibradores de su función. La situación sobre la que actúa la veo yo como de desequilibrio inherente en vez de equilibrio, como

${ }^{25}$ Mises (2009), p. 619.

26 García Paramés (2007). 
un movimiento desordenado de oportunidades de cambios ventajosos, más que como una situación de plácida igualdad. Aunque también, para mí, sólo mediante el empresario pueden tener lugar los cambios, considero estos como cambios equilibradores. Para mí, los cambios que el empresario pone en marcha son siempre hacia ese hipotético estado de equilibrio; son variaciones sugeridas en respuesta a una pauta existente de decisiones erróneas, pauta caracterizada por las oportunidades perdidas. El empresario, creo yo, contribuye al ajuste de estos elementos discordantes consecutivos a la ignorancia previa del mercado. ${ }^{27}$

La conceptualización de este empresario, que busca desajustes y los coordina, y los efectos que ello tiene sobre el proceso de mercado aparece con mayor claridad en la explicación que hace Huerta de Soto del proceso empresarial y el desarrollo de la sociedad:

El proceso empresarial de coordinación social jamás se detiene ni agota. Esto es así porque el acto coordinador elemental [...] consiste básicamente en crear y transmitir nueva información que por fuerza ha de modificar la percepción general de objetivos y medios de todos los actores implicados. Esto, a su vez, da lugar a la aparición sin límite de nuevos desajustes que suponen nuevas oportunidades de ganancia empresarial, y así sucesivamente, en un proceso dinámico que nunca se termina, y que constantemente hace avanzar la civilización. ${ }^{28}$

No cabe pensar que los desajustes se agotan, sino que conforme se van ajustando, van surgiendo nuevos desajustes producto de la satisfacción previa de los anteriores. Es decir que mientras los inversores y empresarios mejor realicen sus actividades, mayor será la eficiencia en el mercado: más coordinados podrán estar los distintos planes de los individuos y menos desajustada estará la estructura productiva de la economía. Conforme más demandas se satisfagan, lo que implica utilizar los recursos con más eficiencia, se eliminan más desajustes con menos recursos,

27 Kirzner (1975), p. 86.

28 Huerta de Soto (2010), pp. 78-79. 
ello abre oportunidades para que los recursos liberados se utilicen para satisfacer una nueva frontera de desajustes, con lo que, progresivamente, en este proceso sin fin, se va creando más riqueza en la sociedad. En todo esto, los inversores que realizan, a lo largo del tiempo y mejor que sus competidores, su función de destinar el capital a las empresas más capaces y subvaloradas, serán aquellos que recibirán las mejores y mayores ganancias.

\section{$\mathrm{V}$ \\ LOS MODELOS MATEMÁTICOS NO AYUDAN A COMPRENDER LOS FENÓMENOS ECONÓMICOS}

Los economistas de la escuela austriaca y los inversores en valor se sienten incómodos ante la idea de que un modelo matemático sea capaz de ofrecer una explicación realista de los procesos económicos o sirvan de guía de inversión. El fundamento de esta idea es doble: debido a que todo aquello que tenga que ver con acción humana pervive en una incertidumbre inerradicable -las empresas son organizaciones llevadas adelante por personas que interactúan con otras personas- $y$, debido a la naturaleza de los modelos matemáticos, cuya resolución es inmediata o atemporal. Los procesos de mercado transcurren en el tiempo, tienden a extenderse, ampliarse y hacerse más complejos e impredecibles dado que sus motores son las acciones de millones de individuos.

Los modelos matemáticos generan una tendencia a ignorar los fundamentos y a desviar el enfoque hacia datos o estadísticas que pretenden capturar toda la información, pero que como no dan cabida a la incertidumbre, no permiten penetrar las complejidades de los procesos de mercado en todas sus dimensiones y matices. El economista Hans Mayer (1879-1955) apuntaba al meollo del problema destacando la simultaneidad de las ecuaciones frente a una realidad que consiste en un proceso de etapas sucesivas:

En esencia, se produce en el corazón de las teorías matemáticas del equilibrio una ficción inmanente, más o menos camuflada: en efecto, todas ellas relacionan mediante ecuaciones simultáneas, 
magnitudes no simultáneas que sólo surgen en una secuencia genético-causal, como si éstas existieran juntas en todo momento. De esta manera, el punto de vista estático sincroniza los acontecimientos, cuando lo que existe en la realidad es un proceso. Sin embargo, uno no puede considerar un proceso genético en términos estáticos, sin eliminar precisamente su más íntima característica. ${ }^{29}$

En referencia al uso de las matemáticas y agregados en la economía, el economista Friedrich A. Hayek (1899-1992), ha dicho:

La mayor ventaja de la técnica matemática consiste en que nos permite describir, por medio de ecuaciones algebraicas, el carácter general de un patrón aun cuando ignoremos los valores numéricos que determinarán su manifestación particular. [...] Sin embargo, esa técnica ha creado la impresión de que podemos utilizarla para la determinación y el pronóstico de los valores numéricos de tales magnitudes; esto ha conducido a una búsqueda vana de constantes cuantitativas o numéricas. [...] Debo confesar que todavía dudo de que su búsqueda de magnitudes mensurables haya hecho alguna aportación importante a nuestro entendimiento teórico de los fenómenos económicos, por oposición a su valor como una descripción de situaciones particulares [...] debo confesar que prefiero el conocimiento verdadero, aunque imperfecto, a pesar de que deje muchas cosas indeterminadas e imprevisibles, a una pretensión de conocimiento exacto que probablemente será falso. ${ }^{30}$

El problema está en que los modelos matemáticos empujan al economista o inversor a poner en un segundo plano la comprensión del proceso que se está gestando. Por ello, los economistas de la escuela austriaca y los seguidores del método de la inversión en valor dudan de la utilidad de los métodos técnicos para ofrecer un criterio válido de inversión. Así, Graham señalaba:

Las matemáticas son ordinariamente consideradas como capaces de producir resultados precisos de los que puedes depender;

${ }^{29}$ Citado en Huerta de Soto (2007), p. 35n.

30 Hayek (1974), pp. 4-5. 
pero en el mercado de valores mientras más elaboradas y sofisticadas sean las matemáticas, más inciertos y especulativos serán los resultados que se obtengan de ellas. En mis 44 años de experiencia y estudios en Wall Street nunca he encontrado cálculos en los que pueda depender sobre los valores de las acciones ordinarias, o vinculados a las políticas de inversión, que fueran más allá de la aritmética básica o álgebra elemental. ${ }^{31}$

De igual forma, el gestor Guzmán de Lázaro señala:

El devenir de las empresas no es modelable, ni puede ser enteramente captado por la matemática o la estadística, porque no pertenece al campo de la ciencia [natural], sino de la acción humana. [...] La evolución de las empresas que prosperan o se hunden no puede, pues, ser captada por modelos ni gráficos porque las acciones humanas son las que la determinan, y éstas son por definición mucho más ricas, variadas e impredecibles de lo que la ciencia [natural] es capaz de captar. ${ }^{32}$

\section{Y Buffett indica:}

El éxito en la inversión no será producido por fórmulas arcanas, programas de computadoras o señales que se iluminan debido al comportamiento de los precios de las acciones o los mercados. En cambio, un inversor será exitoso al combinar su olfato para identificar un buen negocio con la habilidad de aislar sus pensamientos y comportamientos de las emociones supercontagiosas que se arremolinan en el mercado. ${ }^{33}$

El mensaje de fondo es que los modelos matemáticos, aplicados a los ámbitos de la acción humana, son peligrosos para el inversor. En lugar de centrarse en los aspectos claves de un negocio y reconocer los riesgos a los que se expone, los modelos matemáticos esconden los fundamentos financieros, borran la incertidumbre de la ecuación e impulsan al inversor a buscar señales técnicas que sirvan como criterio último de inversión. Por ello,

\footnotetext{
31 Graham (2006), p. 570. Traducción libre.

32 Guzmán de Lázaro (2008).

33 Buffett (2008), p. 79. Traducción libre.
} 
al igual que en la economía, tal y como lo ha explicado Hayek, a pesar de la aparente imprecisión del método de la inversión en valor, el método verbal termina siendo mucho más certero que el técnico.

\section{VI}

\section{HUMILDAD ANTE LAS POSIBILIDADES DE PREDICCIÓN}

En una ocasión se le consultó al empresario estadounidense del siglo XIX, J.P. Morgan, sobre qué iba a suceder en el mercado de valores, y respondió: «Va a fluctuar». $\mathrm{Y}$ es que, como nos dice Graham, «el futuro de los precios de títulos-valores nunca es predecible». ${ }^{34}$ Como señalamos en el apartado anterior, el mundo empresarial no se puede modelar en términos matemáticos. Es vano pretender decir algo sobre aquello cuya situación específica en el futuro dependerá de millones de factores variables, cada uno de los cuales influencia a cada uno de los otros en procesos interminables y abiertos de retroalimentación positiva y negativa. ${ }^{35}$ A propósito, Huerta de Soto escribe:

El futuro es [...] siempre incierto, en el sentido de que aún está por hacer y el actor sólo tiene de él ciertas ideas, imaginaciones o expectativas que espera hacer realidad mediante su acción personal e interacción con otros actores. El futuro, además, está abierto a todas las posibilidades creativas del hombre, por lo que cada actor se enfrenta al mismo con una incertidumbre inerradicable, que podrá minorarse gracias a los comportamientos pautados propios y ajenos (instituciones) y si actúa y ejerce bien la función empresarial, pero que no será capaz de eliminar totalmente. ${ }^{36}$

Debido a la incertidumbre que hay en el ámbito financiero y empresarial, el periodista Jason Zweig, señala que una de las

\footnotetext{
34 Graham (2006), p. 24. Traducción libre.

35 Sobre los procesos de retroalimentación positiva y negativa y la relación entre la teoría del caos y la Escuela Austriaca de Economía, ver Parker y Stacey (2007).

36 Huerta de Soto (2010), p. 46.
} 
lecciones fundamentales de la filosofía de inversión que propugna Graham es que al no poder controlar lo que sucede en el mercado, para poder ser inversores exitosos lo único que nos queda es poder controlar nuestro comportamiento. ${ }^{37}$ Por ello, Buffett y otros inversores se refieren constantemente a la necesidad de contar con paciencia y disciplina emocional como un factor clave del éxito para aguantar los vaivenes del mercado.

Y es que debido a la naturaleza del campo estudiado, no podremos saber más que el patrón general de comportamiento de lo que podría suceder. «Lo que suceda mañana no puede conocerse científicamente hoy, pues depende en gran parte de un conocimiento e información que aún no se han generado empresarialmente y que hoy todavía no pueden saberse; en economía, por tanto, tan sólo pueden efectuarse, como mucho, "predicciones de tendencia" de tipo general, que Hayek denomina pattern predictions. Estas predicciones serán de naturaleza esencialmente cualitativa y teórica y relativas,» explica Huerta de Soto. ${ }^{38}$

Este concepto de predicciones de tendencia lo podemos traducir al ámbito empresarial y financiero, con la distinción que hace Graham sobre las inversiones basadas en las predicciones de movimientos futuros del valor de las acciones frente aquellas inversiones realizadas con base en la idea de contar con un amplio margen de seguridad. Graham argumenta que los criterios de inversión no han de estar basados en las posibilidades de que se acierte o no con una predicción, sino más bien, en la certeza con que se pueda determinar que aun en condiciones adversas, la empresa pueda seguir adelante y que no se compre a un precio caro. Es decir, lo que se busca no es aumentar la certeza en la predicción del precio de la acción, sino de reducir la posibilidad de que la empresa en que se vaya a invertir no se compre a un precio excesivamente alto porque ello aumenta significativamente las posibilidades de pérdidas y, a su vez, que las empresas que se escojan sean empresas cuyas condiciones y cualidades den cierta seguridad sobre su resultado futuro.

\footnotetext{
37 Graham (2006), p. 24.

38 Huerta de Soto (2007), p. 37.
} 
Graham distingue entre dos formas en que un analista e inversor pueden ver el futuro. Uno es el camino de la predicción y el otro, el de la protección:

Aquellos que hacen énfasis en la predicción se esmerarán por anticipar con bastante precisión exactamente aquello que la compañía logrará en los años futuros —en particular si las ganancias mostrarán un crecimiento pronunciado y persistente. Estas conclusiones pueden estar basadas en un estudio muy cuidadoso de tales factores como la oferta y la demanda en la industria - o el volumen, precio y costes - o si no se derivarán de una proyección ingenua basada en una extensión de la línea de crecimiento pasado hacia el futuro. Si estas autoridades están convencidas que las proyecciones a un plazo bastante largo son inusualmente favorables, casi siempre recomendarán la compra de la acción sin prestar mucha atención al nivel en que se está vendiendo en el momento. $[\ldots]$

En contraposición, aquellos que enfatizan el camino de la protección están especialmente preocupados con el precio de la emisión al momento en que se realiza el estudio. Sus mayores esfuerzos están destinados a asegurarse a sí mismos que hay un valor presente con un margen sustancialmente mayor que el precio actual de mercado - margen que podría absorber eventualidades negativas en el futuro. ${ }^{39}$

Por tanto, no se trata de encontrar el modelo que «garantice» un resultado, ni de aumentar la cantidad de información disponible, sino de comprender que una inversión exitosa consiste en escoger una empresa con fundamentos financieros sanos, un buen equipo de gestión y ventajas competitivas, a un precio barato. Si esto se ha hecho, aunque haya momentos en que el valor «liquidativo» de las acciones de las empresas en que se ha invertido esté debajo del precio de compra, si la situación subyacente del negocio no ha cambiado, el inversor puede sentirse seguro del camino tomado.

39 Graham (2006), pp. 364-365. Traducción libre. 


\section{VII \\ EL DISTINTO TRATAMIENTO DE LA IDEA DE RIESGO E INCERTIDUMBRE}

Hemos señalado que en el mundo empresarial el devenir está determinado por acciones humanas, las cuales siempre tienen un grado mayor o menor de incertidumbre. Cada acción se realiza con un objetivo en mente, o como un paso previo para la consecución de uno o más fines. No obstante, al actuar, no hay una certeza absoluta de que se obtendrá el resultado deseado. Mientras más tiempo deba transcurrir, más pasos tengan que realizarse y más compleja sea la acción, mayor será el grado de incertidumbre respecto al éxito de la acción. La actividad empresarial enfrenta una gran incertidumbre por la gran cantidad de pasos, procesos, personas, objetivos conjuntos y actividades que realiza. En muchos casos, tendrán que pasar muchos años antes de poder verificar si las acciones emprendidas darán el fruto esperado.

En este ámbito, a la probabilidad de que ocurra cierto evento se le llama probabilidad de caso o evento único. Se trata de un tipo de evento que la acción humana puede provocar y en el que no se conocen todos los factores determinantes. A esto se le llama incertidumbre porque es imposible conocer las probabilidades de cada resultado o imaginar todas las alternativas. Lo más que se puede decir es que se cree que algún resultado será más probable que algún otro, pero no con base en una probabilidad objetiva y calculable. En este sentido, Huerta de Soto señala:

El carácter abierto e ilimitado de la incertidumbre hace que no sean aplicables al campo de la acción humana las nociones tradicionales de la probabilidad objetiva y subjetiva, ni tampoco la concepción bayesiana desarrollada en torno a esta última. Esto es así, no sólo porque ni siquiera se conocen todas las alternativas o casos posibles, sino porque además el actor tan sólo posee unas determinadas creencias o convicciones subjetivas - denominadas por Mises «probabilidades» de casos o eventos únicosque conforme se modifican o amplían tienden a variar por sorpresa, es decir de forma radical y no convergente, todo su «mapa» de creencias y conocimientos. De esta forma, el actor continuamente 
descubre situaciones completamente nuevas que antes ni siquiera había sido capaz de concebir. ${ }^{40}$

La probabilidad de que ocurra uno de estos eventos relacionados con la acción humana difiere de la de aquellos que se rigen por las probabilidades de clase, en los que se conocen los elementos de comportamiento de la clase entera, pero en los que no se puede predecir el comportamiento de un miembro específico de la clase. La probabilidad de clase suele aplicarse en las ciencias naturales y también, por ejemplo, en los seguros de vida: se puede saber la probabilidad de que en un grupo numeroso de hombres, con un rango de edad, muera cierta cantidad en cierto plazo determinado, pero nunca se podría decir cuál de ellos fallecerá, ni cuándo exactamente sucederá.

En el mundo empresarial, la mayoría de los «riesgos» que se enfrentan no son asegurables, ni mensurables; cada evento tiene ese carácter abierto e ilimitado que hace que no se puedan concebir todas las alternativas. Este nivel de incertidumbre aumenta a medida que se alargan los plazos bajo análisis. Pero a pesar de operar en medio de esta incertidumbre inerradicable, ello no implica que no sea posible reducirla. Para eso, el empresario establece contratos, para crear más previsibilidad en los comportamientos de las personas con que se relaciona, y debe ejercer continuamente la función empresarial para estar al tanto de las demandas del mercado, como una forma de reducir la incertidumbre de los ingresos futuros.

Desde la perspectiva del inversor, la principal fuente de incertidumbre es la de si la empresa escogida será una de las que prospere o se hunda. ¿Cómo identificar aquellas que, como mínimo, no se hundirán y, probablemente, serán exitosas? Primero será necesario identificar aquellas empresas que puedan mantener su competitividad. Si la acción humana es abierta e ilimitada, y las empresas son organizaciones llevadas por personas, entonces el inversor en valor debe dedicar sus esfuerzos a reducir la fuente de incertidumbre que surge por parte de la administración

${ }^{40}$ Huerta de Soto (2010), pp. 46-47. 
y los accionistas de la empresa. Debe invertir en una empresa cuando haya identificado a accionistas comprometidos a largo plazo y a un equipo gestor eficiente y preocupado por el valor que se crea para los accionistas. Guzmán de Lázaro señala que «al invertir en una empresa estamos confiando en la capacidad del equipo gestor de la empresa en cuestión para crear valor. Lo que equivale a confiar en su capacidad para anticiparse a infinidad de "acciones humanas" (las de sus competidores, clientes, proveedores, entorno regulatorio, empleados, etc.) mediante otras acciones humanas (las suyas) que acaben por incrementar el valor de su empresa», y luego concluye, en relación con lo expuesto en los apartados quinto y sexto, referentes al uso de los modelos matemáticos y las posibilidades de predicción: «Parece lógico, pues, pensar que la primera fuente de incertidumbre tiene que ver con el equipo gestor de la empresa. Si se pone ahí el énfasis, se está desde luego más cerca de la realidad que cuando se pone en un modelo matemático».41

Para reducir la incertidumbre que enfrenta el inversor, García Paramés explica:

Nos centramos en cosas muy sencillas. ¿El modelo de negocio es entendible? ¿Es probable que sea esencialmente el mismo en los próximos diez años? ¿Las ventajas competitivas son sostenibles o temporales? ¿Se puede calcular de manera razonada el flujo de caja libre normalizado? ¿Tenemos alguna ventaja adoptando una visión a largo plazo? ¿Están cotizando las acciones con un descuento significativo respecto a nuestra estimación de su valor intrínseco? ${ }^{42}$

Ninguna de estas preguntas se puede responder apropiadamente sin conocer a detalle y en profundidad la empresa. Este procedimiento de investigación es lo que el inversor Philip Fisher llamó el método del scuttlebutt o «lo que dice la gente». Consistía en que a través de entrevistas a clientes, proveedores, ex empleados, actuales empleados, competidores, inversores y vecinos se

\footnotetext{
41 Guzmán de Lázaro (2008).

42 García Paramés (2008).
} 
llegara a poder responder a 15 preguntas imprescindibles para conocer y entender el negocio. Las 15 preguntas incorporaban aquellos «atributos [que] debía tener una compañía para que esta tuviese la mayor probabilidad de alcanzar resultados [que pudieran dar una ganancia de varios ciento por cientos] a sus accionistas». ${ }^{43}$ No se trata, sin embargo, de invertir en empresas que tuvieran respuestas inmensamente positivas a cada pregunta, sino que una gran parte de ellas pudiera ser respondida favorablemente. Lo que se busca, pues, son esos patrones con los cuales se pueda identificar una tendencia de comportamiento futuro o una capacidad de respuesta ante la incertidumbre futura.

No obstante, no se puede eliminar totalmente la incertidumbre. El propio inversor puede cometer errores de estimación aun cuando se haya preocupado por comprender bien el negocio. Por ello se insiste en el margen de seguridad, para garantizar que aunque haya errores de estimación en cuanto al desempeño del negocio, al menos las pérdidas serán menores a aquellas que se sufrirían si se hubiese ignorado el precio de compra. Lastimosamente, en el ámbito financiero se ha perdido el sentido tradicional de la palabra «riesgo», a saber, la probabilidad de sufrir una afectación negativa y ha quedado vinculado a la idea de la volatilidad del precio de la acción o la variación frente a sus semejantes.

Así, el riesgo no se relaciona con las posibilidades de tener pérdidas, y suele medirse a través del indicador Beta. En general, la Beta indica la variación que tiene cierta acción con respecto a los movimientos del índice de referencia (el promedio de la bolsa, por ejemplo). Más específicamente, se miden las variaciones de las tasas de retorno entre una acción específica y el índice de referencia. Mientras más alto es el valor Beta, más «arriesgado» es el valor. Un valor alto de Beta indica que si sube (baja) el mercado, esa acción tenderá a subir (bajar) más que el mercado. Si el valor de Beta es negativo, entonces el precio de la acción se moverá en una dirección opuesta a la del mercado.

Buffett señala que «la definición que dan los académicos de riesgo está lejos del blanco, tanto así que produce resultados absurdos. Por ejemplo, bajo una teoría basada en la variable Beta,

43 Fisher (2003), p. 47. Traducción libre. 
una acción que ha caído sustancialmente en comparación al mercado $[. .$.$] se convierte más "arriesgada" al precio más bajo que$ al precio más alto. ¿Tendría esta descripción sentido para alguien a quien se le ofrece la compañía entera al precio más bajo?». ${ }^{44} \mathrm{~A}$ lo que apunta Buffett es que al momento de considerar una oportunidad de inversión, si se mantienen las demás condiciones iguales, existe mucho menos riesgo de sufrir pérdidas cuando el precio de adquisición es más bajo que antes; mientras más alto es el precio de algo, más riesgo hay de incurrir en pérdidas. Por tanto, no tiene sentido decir que porque el valor de una acción ha caído repentinamente, aumentando su Beta, se ha aumentado el riesgo. Continúa diciendo Buffett:

$\mathrm{Al}$ evaluar el riesgo, un purista de la Beta mirará con desdén la idea de examinar lo que la compañía produce, lo que sus competidores hacen o cuánta deuda emplea la empresa. De hecho, puede ser que prefiera ni siquiera saber el nombre de la empresa. Lo que atesora es el historial de precios de la acción. En contraposición, nosotros felizmente obviaríamos el historial de precios de la acción y, en su lugar, buscamos toda aquella información que profundizará nuestra comprensión del negocio de la empresa. ${ }^{45}$

Como hemos señalado, cuando se trata de probabilidad de casos o eventos únicos, la historia pasada no es el determinante de lo que sucederá, solo se trata de un punto de partida. Así, Buffet nos señala:

Aunque el riesgo no se pueda calcular con la precisión de la ingeniería, en muchos casos puede juzgarse con un grado de precisión que es muy útil. Los principales factores que inciden sobre esta evaluación son: 1) La certeza con que las características a largo plazo del negocio pueden ser evaluadas; 2 ) La certeza con que el equipo de administración puede ser evaluado, tanto en sus habilidades para realizar el potencial total del negocio, como en sus capacidades para emplear sabiamente los flujos de cajas recibidos; 3) La certeza con que se puede contar con la administración para

44 Buffett (2008), p. 91. Traducción libre.

45 Ibíd., pp. 91-92. Traducción libre. 
canalizar las recompensas del negocio a los accionistas y no a sí misma; 4) El precio de compra del negocio; y 5) Las tasas impositivas y la inflación que serán experimentadas y que determinarán en qué grado se reducirá el retorno del poder adquisitivo del inversor sobre su retorno bruto. ${ }^{46}$

Esta concepción del conocimiento necesario para juzgar el nivel de riesgo de sufrir pérdidas en una inversión se asemeja a los comentarios de Hayek sobre la utilidad de las matemáticas en la economía para comprender los fenómenos económicos, tal como vimos en el quinto apartado. Ambos muestran una clara preferencia por conocimientos inexactos o imperfectos, pero ciertos, sobre aquellos aparentemente exactos que, en definitiva, son inútiles. En este sentido, Huerta de Soto coincide y señala que precisamente gracias a la insistencia en comprender los fundamentos de los procesos de mercado, en el largo plazo, el economista de la escuela austriaca, muestra una mejor capacidad de predicción de tendencias:

Aunque las «predicciones [de patrón]» de los austriacos sean tan sólo cualitativas y tan sólo se efectúen en términos estrictamente teóricos, se da, sin embargo, la paradoja de que en la práctica, al ser los supuestos de su análisis mucho más realistas (procesos dinámicos y de creatividad empresarial), sus conclusiones y teorías, en comparación con las elaboradas por la Escuela Neoclásica, incrementan mucho las posibilidades de predecir con éxito en el ámbito de la acción humana. ${ }^{47}$

Regresando al concepto financiero de la Beta, para Graham, la diferencia fundamental en la manera en que tradicionalmente se trata el riesgo en los ámbitos académicos es que se confunde las fluctuaciones de precios con el riesgo de pérdidas irreversibles. Si las circunstancias subyacentes de la empresa no han cambiado, entonces el hecho de que el valor «liquidativo» de una acción esté por debajo del precio de compra no representa una pérdida real para el inversor. En sus palabras:

46 Buffett (2008), p. 92. Traducción libre.

47 Huerta de Soto (2007), p. 60. 
Esta confusión puede evitarse si aplicamos el concepto de riesgo solamente a la pérdida de valor que puede realizarse, si de hecho se realiza la venta, o si ha habido un deterioro significativo de la posición de la compañía —o, tal vez con mayor frecuencia, resulta de haber pagado un precio excesivamente alto en relación al valor [estimado] del título. ${ }^{48}$

Las fluctuaciones del precio son un asunto que debe estar alejado de las preocupaciones del inversor. Si de hecho ha realizado su trabajo correctamente, puede sentirse seguro a pesar de los vaivenes y esperar hasta que el mercado termine por reconocer su valoración. Es por ello que Graham sugiere: «La cotización en el mercado siempre estará ahí para aprovecharse de ella en los momentos propicios - sea para compras a precios muy bajos e inusualmente atractivos o sea para vender cuando los precios se encuentran definitivamente muy altos». ${ }^{49}$ En suma, el riesgo de pérdida para el inversor se reduce teniendo un marco teórico para identificar los fundamentos financieros que dan alerta de una empresa sana y rentable, que permite comprender las instituciones externas e internas que generan incentivos para que la acción humana se dirija hacia la creación de valor, que motiva a aceptar que se puede encontrar un excelente negocio que es demasiado caro y que insiste en disciplinar nuestro comportamiento para comprar no lo que nos gusta, sino sólo aquello que nos gusta a un precio barato.

\section{VIII \\ CRÍTICA A LA HIPÓTESIS DE LOS MERCADOS EFICIENTES}

El periodista Zweig relata una broma sobre la Hipótesis de los Mercados Eficientes (HME) que captura muy bien la falacia de esta teoría: «Un viejo chiste cuenta que hay dos profesores de finanzas caminando en una acera; de repente, uno de ellos descubre un billete de $\$ 20$ y se agacha para recogerlo, pero el otro profesor

48 Graham (2006), pp. 121-122. Traducción libre.

49 Graham (2006), p. 359. Traducción libre. 
le agarra el brazo y le dice, $\mathrm{Ni}$ te preocupes. $\mathrm{Si}$ en verdad fuera un billete de $\$ 20$, alguien ya lo hubiera recogido». ${ }^{50} \mathrm{Y}$ es que, según nos explica el economista Frank Shostak, de acuerdo con la $\mathrm{HME}$, «la eficiencia del mercado significa que el inversor individual no puede ser más listo que el mercado al intercambiar basándose en la información disponible». ${ }^{51}$

Según uno de los principales promotores de la HME: «La teoría sostiene que el mercado aparenta ajustarse tan rápidamente a la información sobre títulos-valores individuales, y la economía en general, que no hay técnica alguna —ni de análisis técnico o de análisis de fundamentos financieros- que permita seleccionar una cartera que consistentemente pueda mostrar un resultado superior al de una estrategia que consista en comprar $\mathrm{y}$ mantener un grupo diversificado de valores» $\mathrm{y}$, luego, añade que «un mono con los ojos vendados tirando dardos a las páginas financieras de un diario puede seleccionar una cartera que fuera tan bien como la seleccionada por un experto». ${ }^{52}$ Ello implicaría que cualquier resultado superior al promedio del mercado no puede deberse a otra cosa que a la suerte. Adicionalmente, esta teoría requiere que se suponga que la información está siempre inmediatamente disponible a todos los participantes por igual e, incluso, que todos los participantes interpretarán la información de la misma manera, lo cual es contrario a lo que sucede en la realidad e imposible científicamente dadas las circunstancias de tiempo y lugar de cada persona, sus intereses, conocimientos, experiencias y preferencias.

Todo ello apunta a que la HME contiene una contradicción interna: si ya los mercados reflejan la valoración de toda la información disponible, cualquier cambio en una valoración se debe a razones puramente aleatorias y exógenas. Es decir, no puede surgir un cambio endógeno, porque nadie puede actuar con base a la información nueva o, dicho de otra manera, quiere decir que no existe la acción ni el libre albedrío. Ya supone que se ha actuado. Por ello, a pesar de su popularidad en el ámbito financiero

\footnotetext{
50 Graham (2006), p. 363n. Traducción libre.

51 Shostak (1997), p. 28. Traducción libre.

52 Malkiel (1985), p. 194, citado por Shostak (1997), p. 28. Traducción libre.
} 
y académico, la HME no debe utilizarse como marco teórico para comprender los procesos de mercado o para invertir.

Sobre la HME, Buffett señala que muchos inversores

estaban bajo el hechizo de los académicos en las prestigiosas escuelas de negocios que estaban predicando la teoría recién creada: el mercado de valores era totalmente eficiente y, por tanto, los cálculos del valor de negocios - hasta el pensamiento en sí mismo- no tenían importancia alguna en el mundo de las inversiones. (Estamos enormemente endeudados con esos académicos: ¿Qué pudiera ser más ventajoso en un concurso intelectual — sea en el bridge, el ajedrez o la selección de acciones-que el contar con oponentes a quienes se les ha enseñado que el pensar es un desperdicio de energía?). ${ }^{53}$

$\mathrm{Y}$ es que para obtener resultados sostenibles y consistentes a lo largo del tiempo, la decisión de inversión no puede ser dejada al azar. La falacia de esta teoría se pone de manifiesto cuando pensamos en el proceso de análisis que se haría de una empresa privada que no está cotizando en la bolsa de valores. En ese caso, siempre se consideran los fundamentos de la empresa, la rentabilidad, las ventajas competitivas, los gestores, etc. ¿Por qué habría de cambiar esto sólo porque la empresa cotiza en la bolsa?

Desde la perspectiva de la ciencia económica, el problema está en que desaparece el papel del empresario en la economía como agente de coordinación y ajuste de desequilibrios. En la realidad, no puede haber procesos de mercado si no se ejerce la función empresarial. Pero de la HME, lo que se desprende es un desdén del empresario, ya que su actividad no puede diferenciarse del azar. Si, según dice, la información ha sido absolutamente recogida y valorada en el mercado, el empresario no tiene razón de ser.

Si utilizamos como base la definición de empresarialidad de Huerta de Soto, a saber, «la capacidad típicamente humana para darse cuenta de las oportunidades de ganancia que surgen en el entorno actuando en consecuencia para aprovecharse de las

53 Buffet (2008), p. 77. Traducción libre. 
mismas», ${ }^{4}$ se tendría que concluir que bajo la HME, no hay oportunidades de ganancia. Y si no hay oportunidades de ganancia, entonces no se puede ejercer la función empresarial porque no hay desajustes que coordinar. El error fundamental de la HME difiere poco del modelo de equilibrio neoclásico, es decir, establecer como punto de referencia un ideal que no es posible en el mundo real, omitir a los protagonistas y, desde allí, analizar la realidad.

En cambio, el criterio de eficiencia dinámica de Huerta de Soto resulta mucho más enriquecedor y fértil para el inversor o empresario, ya que les da un marco teórico para visualizar el mercado y comprender sus funciones. A saber, que le corresponde la tarea de encontrar desajustes y desequilibrios y actuar para eliminar ese desajuste, o dicho de otra manera, que si encuentran oportunidades de ganancias y actúan para obtenerlas, están dándole un tremendo servicio a la sociedad al colaborar de manera significativa en el proceso de coordinación y eliminación de desajustes. ${ }^{55}$ Estos ajustes implican que se han satisfecho necesidades y que se ha creado riqueza, dando espacio para la persecución de nuevos fines por parte de todas las personas que participan en el proceso.

\section{IX \\ CÁLCULO ECONÓMICO, GANANCIAS EMPRESARIALES Y EL RETORNO SOBRE CAPITAL INVERTIDO}

En la economía se distingue entre lo que es una ganancia ordinaria acorde con la tasa de interés ${ }^{56}$ natural en el mercado frente a las ganancias extraordinarias o empresariales. Si la actividad o inversión genera una ganancia superior a la tasa de interés natural del mercado, o por encima del coste de capital requerido, se dice

\footnotetext{
54 Huerta de Soto (2004), p. 26.

55 Ibíd., p. 29.

56 Podemos definir la tasa o tipo de interés como el precio de mercado de los bienes presentes en función de los bienes futuros (Huerta de Soto 2009, p. 228). A efectos prácticos, la tasa de interés mínima que compararía el inversor sería la que pudiera obtener en una inversión de similar cantidad de dinero a un plazo de, digamos, 5 años, en, por ejemplo, un préstamo entregado a un banco de primera.
} 
que existen ganancias empresariales o extraordinarias. Estas serían el tipo de ganancias que atraerían capital a esa actividad, y lo detraerían de actividades que pierden o ganan por debajo de la tasa de ganancia ordinaria. ${ }^{57}$

Cachanosky apunta: «Según las definía [Adam] Smith, las ganancias ordinarias son aquellas que no atraen o expulsan capitales de un determinado sector productivo. Por el contrario, una ganancia extraordinaria es la que provoca ingresos de nuevas inversiones al sector. Si, en cambio, la ganancia está por debajo de la ordinaria, los capitales se retiran del sector». ${ }^{58}$ Pero Cachanosky luego añade, en sintonía con la crítica que venimos haciendo a la HME, que «para los economistas de la escuela austriaca la ganancia empresarial sólo se da si los ingresos por ventas superan a "todos" los costes (incluso el de capital) involucrados en el proceso productivo. Y esto puede ocurrir sólo en un mundo de información dispersa. Bajo condiciones de conocimiento perfecto no habría oportunidades de ganancias empresariales, porque el mercado arbitraría instantáneamente». ${ }^{59}$ En otras palabras, las ganancias empresariales se obtienen cuando el Retorno sobre capital invertido (ROIC, Return on Invested Capital) o el Return on Capital Employed (ROCE), es mayor que la tasa de interés natural del mercado y el coste de capital (estimado por el inversor, pero que es superior a la tasa de interés). Puede decirse, pues, que el inversor no solo busca que el rendimiento de su inversión supere la tasa de interés natural, sino que supere el coste de capital, de tal manera que se justifique el esfuerzo y los riesgos asumidos. De no ser así, por qué emprender esos esfuerzos si puede obtener un retorno similar con un menor esfuerzo colocando el dinero en un depósito a plazo fijo. Participar en este proceso exige el ejercicio de la función empresarial. El empresario y el inversor, a medida que va poniendo a prueba sus decisiones e inversiones, va realizando el cálculo económico con lo cual puede determinar en qué áreas está siendo más o menos exitoso en emplear el escaso capital.

57 Con respecto a los tipos de interés y los beneficios contables, consultar Huerta de Soto (2009), p. 231.

58 Cachanosky (1999), p. 1.

59 Ibíd. 
Si el cálculo económico nos indica si estamos invirtiendo apropiadamente el capital, entonces, ¿qué debe hacer el inversor para determinar si se está obteniendo estas ganancias empresariales? La primera idea es dirigirnos a verificar en el estado de resultados el beneficio neto. Pero el «beneficio neto», tal como aparece en los estados financieros, no es una buena referencia para determinar la rentabilidad real sobre el capital invertido, como tampoco lo son los indicadores de rendimiento sobre patrimonio o el margen de beneficio que se calculan tradicionalmente. Esto se debe a que el beneficio neto está afectado por el método utilizado para calcular el valor del inventario, por la regla de depreciación que se use, por la manera en que se contabilizan los gastos en investigación y desarrollo, por la forma en que se contabilice la adquisición de una empresa y por los cambios en valoración de otros activos. Esto genera múltiples variaciones en el «beneficio neto». Por último y más importante, el problema es que el beneficio neto mezcla el resultado operativo con el método de financiamiento del negocio (que suele ser una mezcla de créditos a corto y largo plazo con el capital propio).

Para obtener un mejor cálculo del verdadero retorno sobre una inversión, lo primero que se debe hacer es eliminar el efecto distorsionador que producen en el indicador de beneficio neto las distintas fuentes de financiación. Para ello, se calcula la ganancia neta operativa después de impuestos, lo que en inglés y el argot financiero se conoce como NOPAT (Net Operating Profits After Taxes). El NOPAT es un valor contable de beneficio que es independiente de la estructura de financiamiento de la empresa y, por ello, corrige uno de los principales problemas del beneficio neto. El NOPAT se calcula de la siguiente manera:

\section{NOPAT $=$}

(Beneficio Operativo - Inversiones de mantenimiento) $\mathrm{x}$ (1 - Tasa impositiva)

El beneficio operativo es la ganancia antes del pago de intereses e impuestos y sin las deducciones por depreciación y amortización; es mejor conocido como EBITDA, o Earnings Before Interests, 
Taxes, Depreciation and Amortization. Las inversiones de mantenimiento corresponden a lo que se conoce como el Capex (Capital Expenditures) de mantenimiento, es decir, el capital que es necesario invertir durante el periodo analizado para mantener en condiciones óptimas los inmuebles y equipos existentes y así salvaguardar el nivel de producción actual. Cabe notar que aunque tradicionalmente el NOPAT suele calcularse utilizando el EBIT (Earnings before interests and taxes), o las ganancias operativas antes de los intereses e impuestos, es más conveniente utilizar como base el EBITDA y restar el Capex de mantenimiento porque producirá una cifra mucho más real. ${ }^{60}$ La depreciación, aunque en efecto intenta reflejar algo que sucede en la realidad, el desgaste que sufren los activos, no nos indica en verdad cuánto se está invirtiendo para mantenerlos.

Una vez calculado el NOPAT, el siguiente paso es determinar el Capital Invertido. Para ello, se toman los activos fijos materiales, como los inmuebles, maquinarias y equipos, y los activos fijos intangibles como las inversiones en investigación y desarrollo y las aplicaciones informáticas (software), etc. A ello se le suma el neto del Capital Circulante (Working Capital). El Capital Circulante Neto se calcula sumando las Cuentas por Cobrar y el Inventario y luego restando las Cuentas por Pagar.

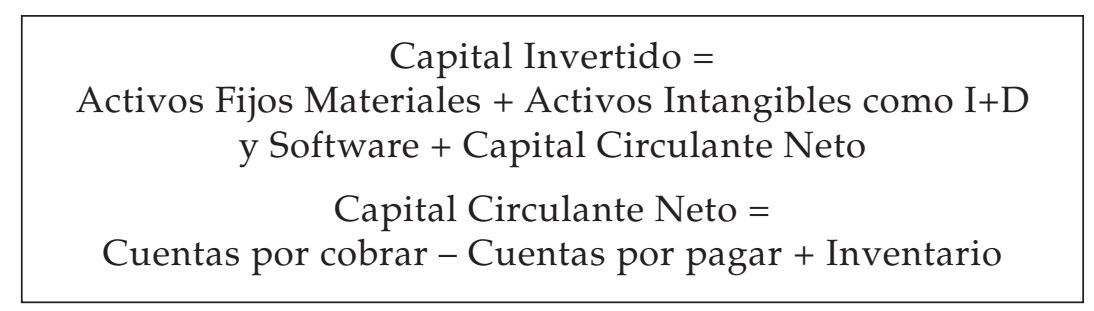

Luego, dividimos el NOPAT entre el Capital Invertido, lo que nos da el retorno sobre capital invertido (ROIC). ${ }^{61}$

60 Entrevista a Fernando Bernad, gestor de fondos de Bestinver. Agradezco a Fernando Bernad por el grueso de los argumentos presentados a continuación en este apartado. Cualquier error u omisión es mi responsabilidad.

61 Puede hacerse la acotación de que es posible calcular el ROIC para el negocio frente al ROIC de la compañía. El ROIC tal como se ha expuesto en este trabajo 
ROIC $=$ NOPAT / Capital Invertido

Desde la perspectiva de la economía austriaca, si este retorno es mayor al costo de capital, entonces se estarán generando ganancias empresariales. Mises nos dice que «la única fuente de la que brota el beneficio del empresario es su capacidad para prever, con mayor justeza que los demás, la futura demanda de los consumidores». ${ }^{62}$ En este sentido, las actividades empresariales que están generando ROICs altos, suponiendo un mercado poco o nada intervenido por el Estado, están generando este tipo de ganancias empresariales, lo que implica, en el transcurso del proceso de mercado, que se están ajustando y coordinando de la mejor manera posible los planes individuales de cada persona en el mercado, satisfaciendo demandas y utilizando con mayor eficiencia los recursos disponibles.

En principio, un inversor en valor busca empresas que tienen ganancias empresariales muy altas y que probablemente serán capaces de mantenerlas en el futuro, pero cuyas rentabilidades aún no ha sido reconocidas o descubiertas por el mercado. Con el ROIC se puede determinar la eficiencia con que es utilizado el capital en la empresa bajo evaluación. De cara al futuro, como las circunstancias en que opera la empresa bajo evaluación nunca se mantendrán igual, no solo le vale al inversor en valor determinar el margen de seguridad que parece tener la acción hoy. Este es un análisis estático y si solo se tomase esto en cuenta, se pudiera caer en lo que se conoce como una «trampa de valor». Es decir, que aunque la empresa haya mostrado buenos retornos hasta ahora, el precio barato de compra de la acción pudiera reflejar que el mercado está estimando correctamente la falta de capacidad de la administración de poder mantener esos retornos. Por ello, el inversor en valor debe considerar la capacidad de la empresa para mantener ese nivel alto de retorno hacia el futuro, en

corresponde al ROIC del negocio. No obstante, pudiera incorporarse en el cálculo de capital invertido el intangible correspondiente al fondo de comercio pagado en las adquisiciones de otras empresas para calcular el ROIC de la compañía.

62 Mises (2009), p. 353. 
las circunstancias cambiantes del mercado. Además de estudiar el historial financiero y verificar la capacidad que ha mostrado de mantener márgenes operativos, conviene identificar las facultades del equipo de gestión, evaluar el programa de investigación y desarrollo y la regularidad con que logra incorporar productos o servicios que ofrezcan valor al mercado, sus ventajas competitivas y las barreras de entrada a nuevos competidores, sus relaciones con proveedores y clientes, la transparencia en sus cuentas, la disposición a hablar con franqueza sobre los errores cometidos y las relaciones con la fuerza laboral, entre otros factores. Esto sería el análisis dinámico y prospectivo.

$\mathrm{Si}$ el inversor logra encontrar respuestas favorables a estas preguntas y, sobre todo, si la empresa tiene buenas ventajas competitivas que puede mantener, es probable que haya encontrado una empresa que pueda seguir generando ROICs altos de manera sostenida y a largo plazo. Pero solo si se invierte cuando hay un alto diferencial entre el precio de compra y el valor estimado por el inversor, se contará con un margen de seguridad. Si se dan estas dos condiciones, entonces a medida que pasa el tiempo y la empresa continúa creando valor, el valor de la acción estimado como razonable por el inversor también continuará creciendo, aumentando el margen de seguridad e incrementando las posibles ganancias, siempre y cuando se tenga la paciencia necesaria para esperar. En este proceso, el inversor debe seguir evaluando las circunstancias y desempeño de la empresa, porque si el precio de la acción sube, el inversor debe saber cuándo es un momento adecuado para vender. Si la empresa no ha crecido, entonces una vez el precio de la acción se acerque al valor razonable estimado por el inversor, la acción se debe vender. Pero si la empresa ha continuado creciendo, manteniendo sus ventajas competitivas y su rentabilidad, el inversor debe saber que debe quedarse con su inversión. 


\section{$X$ CONCLUSIÓN}

En este ensayo hemos argumentado que existe una gran compatibilidad y complementariedad entre la escuela austriaca de economía y el método de inversión en valor. Además de que ambos comparten una visión filosófica fundamental del mundo económico, hemos desarrollado nueve aspectos en los cuales existe una convergencia entre ambas perspectivas. Los nueve aspectos, si bien exploran áreas distintas, están íntimamente relacionados entre sí. Están vinculados a las ideas de que existe una incertidumbre en el ámbito de la acción humana que nunca se puede erradicar totalmente, a la necesidad de usar supuestos realistas y a la importancia de ser prudentes de cara al futuro.

La escuela de economía austriaca ofrece un marco teórico que permite al inversor comprender mejor los procesos de mercado, la razón de ser de su actividad y el beneficio que provee a la sociedad la buena ejecución de sus tareas. Por su parte, el economista, mediante la comprensión del método de la inversión en valor, obtiene una visión mucho más clara y práctica sobre la forma en que se realiza el cálculo económico, el significado de los beneficios económicos y la importancia de los mercados de valores. $Y$ es que no se puede analizar el mercado bursátil como si operara con independencia de las realidades subyacentes. Si bien es posible que en el corto plazo los movimientos puedan parecer caóticos, lo cierto es que las vicisitudes del mercado dependen en última instancia de la capacidad de las empresas encarnadas en esos títulos de satisfacer las necesidades de sus clientes. Por tanto, los mejores métodos de inversión serán aquellos que buscan identificar las empresas que demuestren ser capaces de satisfacer de la mejor manera a sus clientes, haciéndolo de manera más barata y eficiente que sus competidores. El corolario de esta conclusión es que no es la toma de más riesgo lo que genera más ganancias, sino la capacidad del empresario para ajustarse a las demandas de sus clientes y a mantener una ventaja competitiva frente a sus competidores.

El inversor en valor no busca predecir lo que hará el precio de la acción la semana o el mes que viene, sino identificar ciertos 
patrones de conducta dentro de la empresa y las ventajas competitivas con que cuenta, que aseguran que si se tiene la paciencia para esperar algunos años, ante la rentabilidad y éxito demostrado por la empresa, el mercado se verá obligado a reconocer y no ignorar la capacidad de creación de valor de la empresa. La recompensa del inversor en valor proviene de haber descubierto esas capacidades y ventajas competitivas a un precio que a todas luces ignoraba esa realidad, haber invertido y tenido la paciencia para esperar el largo periodo, que puede ser de varios años, hasta que el mercado lo termine por reconocer.

El tipo de predicciones que puede realizar el economista también es de este tipo, es decir, no se trata de predecir el cuándo exacto de un evento. Pero conociendo la serie de circunstancias existentes e instituciones que están gobernando una serie de relaciones, se puede decir con seguridad que de ahí surgirá, o probablemente continuará ocurriendo, un patrón particular de comportamientos que podrán ser negativos o positivos, lo cual tenderá a producir una serie de eventos en lugar de otro tipo de eventos. Curiosamente, dada la inercia de los procesos de mercado, le suele suceder al economista de la escuela austriaca algo muy similar a lo que enfrenta el inversor en valor: el economista de la escuela austriaca deberá tener la suficiente paciencia para poder aguantar la contracorriente de opiniones y esperar hasta que se pongan de manifiesto los desbalances en la estructura productiva de la economía causados por el patrón negativo que había identificado.

Por último, pensamos que los vínculos existentes entre la escuela austriaca de economía y el método de inversión en valor se pueden aprovechar en el espacio académico para integrar el estudio de las finanzas y la administración de empresas con las ciencias económicas, especialidades que en los programas educativos de hoy día parecen estar solo remotamente relacionadas. Como hemos apuntado, la economía austriaca le asigna al empresario un papel primordial en el proceso de mercado, pero en el paradigma neoclásico, el más popular en las facultades de economía, el empresario tiene poco o nada que ver con el desenvolvimiento de los fenómenos económicos. A su vez, el método de la inversión en valor permite rescatar y hacer énfasis sobre la importancia 
del cálculo económico en una realidad en la que la información está dispersa y hay una incertidumbre inerradicable.

\section{REFERENCIAS BIBLIOGRÁFICAS}

BENEGAS Lynch (h), A. (2011 [1972]): Fundamentos de análisis económico, 12.. ed. ampliada, Panamá, Ediciones Sociedad Abierta.

Buffett, W. (2008 [1997]): The Essays of Warren Buffett: Lessons for Corporate America, Selected, arranged and introduced by L.A. Cunningham, $2^{\text {nd }}$ ed., Curham, Carolina Academic Press.

CACHANOSKY, J.C. (1986): «La ciencia económica vs. la economía matemática (II)», Revista Libertas, N.․․ 4, Mayo 1986. Instituto Universitario ESEADE. http:/ / www.eseade.edu.ar/ servicios/Libertas/46_4_Cachanosky.pdf.

- (1999): «Value Based Management», Revista Libertas, N.․ 30, Mayo 1999, Instituto Universitario ESEADE. http: / / www. eseade.edu.ar/servicios/Libertas/14_7_Cachanosky. pdf.

FisHer, P.A. (2003 [1958]): Common Stocks and Uncommon Profits, preface and introduction by Kenneth L. Fisher, Hoboken, NJ, John Wiley \& Sons.

García Paramés, F., Guzmán de Lázaro, A. y Bernad, F. (2007): Entrevista: «Bestinver - En la cumbre de la inversión en valor europea», European Value Investor. N. 1, dic. 2007. http:/ / www.bestinver.es/opinion.aspx?tab=2.

García Paramés, F. (2006): «¿Por qué invertir en Bestinver Internacional?», 1 de abril de 2006. http:/ / www.bestinver.es / opinion. aspx?tab=3.

- (2007): «¿Existe el valor objetivo de un activo?», $27 \mathrm{de}$ febrero de 2007. http: / / www.bestinver.es/opinion.aspx?tab=3.

- (2008): Entrevista: «Una migración excelente», Value Investor Insight, 26 de noviembre de 2008. http: / / www.bestinver.es / opinion. $a s p x ? \operatorname{tab}=2$.

- (2011): «Entrevista a Francisco García Paramés», Wealth Insight, Mayo 2011. http:/ / www.bestinver.es/opinion.aspx?tab=2.

Graham, B. (2006 [1973]): The Intelligent Investor: The Definitive Book on Value Investing, revised ed., Preface and Appendix 
by Warren E. Buffet, Updated with new commentary by Jason Zweig, New York, Harper.

Grant, J. (1996): Interview: «The Trouble with Prosperity», Austrian Economics Newsletter, Winter 1996, Vol. 16, N. 4. http://mises.org/journals/aen/aen16_4_1.asp.

GUZMÁN DE LÁZARO, Á. (2006): «Mi visión de la gestión», 1 de abril de 2006. http:/ / www.bestinver.es/opinion.aspx?tab=3.

- (2008): "Value investing y escuela austriaca de economía», 15 de septiembre de 2008. http://www.bestinver.es/ opinion.aspx?tab=3.

HAYEK, F.A. (1974): «La pretensión del conocimiento», discurso de aceptación del Premio Nobel de Economía, 11 de diciembre de 1974, traducido por Movimiento Libertario de Costa Rica, Instituto Cato. Original en inglés, «The Pretense of Knowledge», en http:/ /www.nobelprize.org/nobel_prizes / economics / laureates/1974/hayek-lecture.html

Huerta DE Soto, J. (2004): «La teoría de la eficiencia dinámica», Procesos de Mercado: Revista Europea de Economía Política, vol. I, n.. 1, Primavera 2004, pp. 11-71.

- (2007 [1996]): «El Methodenstreit, o el enfoque austriaco frente al enfoque neoclásico en la ciencia económica», Cap. I en Nuevos estudios de economía política, Madrid, Unión Editorial.

- (2009 [1998]): Dinero, crédito bancario y ciclos económicos, 4. ${ }^{\text {a }}$ ed., Madrid, Unión Editorial.

- (2010 [1992]): Socialismo, cálculo económico y función empresarial, 4. ${ }^{a}$ ed., Madrid, Unión Editorial.

KIRZNER, I.M. (1975): «El empresario», Cap. IV en Huerta de Soto, J. (2009 [1986]) Lecturas de economía politica, vol. I, Madrid, Unión Editorial. Corresponde al Cap. II de Competencia y función empresarial, Madrid, Unión Editorial, 1975.

LeithNer, C. (2005): «Ludwig von Mises, Meet Benjamin Graham: Value Investing from an Austrian Point of View», en Mises.org, preparado para la conferencia «Austrian Economics and Financial Markets», Las Vegas, 18-19 de febrero de 2005. http:/ / mises.org/journals/scholar/Leithner.pdf.

LONG, R.T. (2006): «Realism and Abstraction in Economics: Aristotle and Mises versus Friedman", Quarterly Journal of Austrian Economics, Vol. 9, N. 3 (Fall 2006): 3-23. 
MalKiel, B.G. (1985): A Random Walk Down Wall Street, New York, W.W. Norton.

Martínez Meseguer, C. (2006): La teoría evolutiva de las instituciones: la perspectiva austriaca, Madrid, Unión Editorial.

Mises, L. (2009 [1949]): La acción humana: tratado de economía, 9. ․ ed., Madrid, Unión Editorial.

Parker, D. y StaceY, R. (2007 [1994]): Chaos, Management and Economics: The Implications of Non-Linear Thinking, London, Institute for Economic Affairs. Disponible en http: / / accessible. iea.org.uk/files/upld-book89pdf?.pdf.

QUIJANO DURÁN, D.E. (2011): «La inversión en valor y la economía austriaca», La Ilustración Liberal, N. 50 (invierno 2011): 37-42.

RALLO, J.R. (2011): «Los fundamentos económicos del value investing», 3 de abril de 2011, en Juan Ramón Rallo, página personal, http:/ juanramonrallo.com/03/04/2011/losfundamentos-economicos-del-value-investing/.

SHOSTAK, F. (1997): «In Defense of Fundamental Analysis: A Critique of Efficient Market Hypothesis», Review of Austrian Economics, 10, n.․․ 2: 27-45.

ZANOTTI, G. (2004): «El método de la economía política», Revista Libertas, N.. 40, Mayo 2004, Instituto Universitario ESEADE. http://www.eseade.edu.ar/servicios/Libertas/1_7_ Zanotti.pdf. 